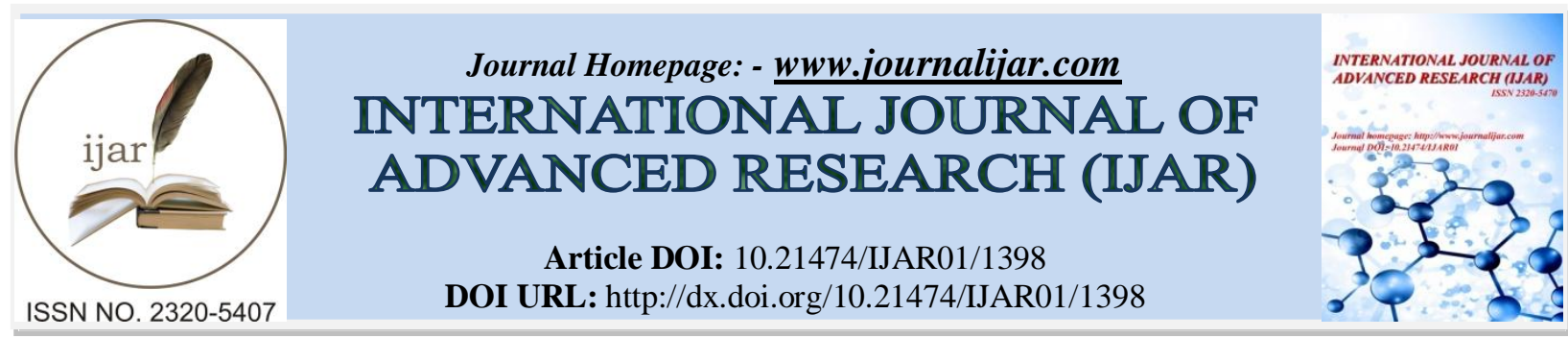

RESEARCH ARTICLE

\title{
EVALUATING HORRIFIC CINEMA FROM THE HYPOTHESES OF PSYCHOLOGICAL EFFECTS ON COLLEGE STUDENTS OF TWO CITIES OF PAKISTAN.
}

\section{Mudassar Hussain Shah ${ }^{1}$, Saima Kausar ${ }^{2}$ and Ashok Kumar ${ }^{3}$.}

1. Department of Communication Studies, University of Sargodha, Sargodha- Pakistan.

2. Department of Mass Communication, Queen Mary College, Lahore-Pakistan.

3. College of Management, Wuhan University of Technology, 122 Luoshi Road, 430070 Wuhan- People's Republic of China.

\section{Manuscript Info}

Manuscript History

Received: 15 June 2016

Final Accepted: 19 July 2016

Published: August 2016

Key words:-

Horror movies; Psychological effects; Desensitization; Youngsters; Prior Believe; Pakistan

\section{Abstract}

The present study explores the psychological effects and to know the reasons which appeal the youngsters to watch horror movies. The exposure to horror movies consequently results some effects which are not same upon all the viewers in intensity and nature because of their gender, environment and prior beliefs about the objects which are shown in horror movies. Social cognitive theory provides a fundamental framework to this research. Applying social cognitive theory which claims that the viewers are proactive and their environment, self-efficacy and self-reflexiveness plays a major role in their learning process. The literature describes that what makes some people to love the horror movies and why some people avoid them? The data is collected from the 640 male and female university students of Sargodha and Lahore cities of Pakistan through survey research. The findings of the study reveal that horror genre is second most popular genre after romantic genre in movies. Entertainment and curiosity are the two main reasons of the youngsters for which they expose to horror movies. The female respondents have significant psychological effects of horror movies contrast to male. The pre-existing beliefs on horror characters or supernatural objects have relationship with the elements of fear. The results also reflect the repetitive effect that causes desensitization on viewers. The policy Implication of the study is to make obligatory movie rating and mass media literacy, can cap the psychological effects of horror movies on youth.

Copy Right, IJAR, 2016,. All rights reserved.

\section{Introduction:-}

Movies are one of the contents which are produced for entertainment. Movies are enjoyed by almost every age group and caste of people. But people differ in their movie viewing choices according to their age, gender, mood, and choice.

Corresponding Author: Mudassar Hussain Shah.

Address: Department of Communication Studies, University of Sargodha, University Road, SargodhaPakistan. 
Movies have become an important tool of entertainment, began small at their origins and gradually grown in 1910 . The film industry evolved and progressed in 1910's from "an industry dominated by mom-and-pop businesses to a mature, complex industry" (Mezias and Kuperman, 2001).

It is said that the movie audience played the role of catalyst for this change in the industry. As this industry grew, competition has also increased. Producers came with different and unique subjects and stories to attract the audiences. Horror genre also attracted the audiences because of having fantasy, thrill, action and suspense in it. The process of evolution in the history of horror films continued because the level of fear that is portrayed by the film is large in part due to the special effects that are present.

Anything to which we often expose obviously has some effects on us whether physically or mentally. With the development of this industry researchers have examined the effects of movies on audiences and got significant results. An age old debate remains on the question that whether or not horror movies have a definite negative effect on the human psyche and mental health. It is also believed that by passing the years, each generation befallen more desensitize to disturbing images of any kind. The purpose of conducting this research is to know the psychological effects of horror movies on the youngsters. A person, who has recently watched a scary movie, might be unable to sleep for a night and then forget about it or this situation remains for weeks and months and the person starts to use night bulb.

Youngsters are fond of watching something full of suspense and thrill. But this is also a fact that where some people love to be afraid by scary movies, there are also some who hate scary flicks. Our desire to understand the unknown is not the only reason and cannot completely explain our interest in scary fantasies. So this research will also help to know the reasons which appeal the youngsters to watch horror movies.

Horror is a natural feeling and the basis for all our nightmares. It is possible that it is rooted in ancient practices to sit around a campfire and telling ghost stories each other by the people. It may be the reason that many of the scary movies and television series start with a scene that someone starting to tell a story at night. The audience will be aware that they are about to be told something frightening and scary. An example of this technique can be seen in The Fog (A movie directed by John Carpenter in 1979) (Giannetti and Leach1999).

Desensitization theory states that the repeated exposure of anything makes the people desensitize to it. They do not remain much sensitive about it. In this context of horror movies, desensitization means that people who watch these movies on regular bases contrast to those who rarely expose to these movies.

\section{Why do people expose to horror movies:-}

The horror genre is being watched globally and by every social class, having a great degree of difference between people in the amusement provided by these films. Leathers and Eaves (2015) cited Palmer (1989) that the unique dissimilarities in the behavior of horror film viewing between people and to find the definite individual features which predict the physiological reactions to the viewing of horror film. There are two conditions in the research. The first condition, the questionnaire-only contain only the opinion poll that is reserved for the individuals who mentioned a disliking towards the horror films and the second condition, the questionnaire-psychology contains the ones who showed liking towards the horror films, these people were presented a film which contains horror clips and the physiological variables such as heart rate, the blood pressure and the skin conductance were being checked. In the group analysis, an insignificant trend was seen for an increased fearlessness in questionnaire-psychology comparative to questionnaire-only condition. The only physiological indication that increased remarkably from the baseline to film was the systolic blood pressure. Moreover, increases in systolic blood pressure having an inverse relation with the Fearlessness and has positive relation with the cold-heartedness. The results put forward the imbalance in personality among the people which view horror films and the ones who don't. Moreover, it put forward physiological dissimilarities among the ones who view horror movies.

Four major areas of motivation among teenager for watching horror films are identified by Johnston (1990) i.e. bloodshed watching, excitement watching, independent watching, lastly the problem watching. These motives reflect reactions to visual films and are having relation with the viewer's intellectually conscious and impressive responses about the film. According to Walton (1978), there isn't any fear when someone watch a film because of the fact that he consciously knows that he is safe. He argues that fear is to believe that the person is not safe. Walton mentioned it as the make-believe theory. However, Morreall (1993) contrary to Walton and argues that fear can 
adopt various insentient shapes. It's not necessary to see Tornado in order to afraid of it. We can also be afraid for other that is the major case for the person who watches movies. These people don't have any fear for their own life unless they suffer by any incident, but they have fear for the movie character.

Bevann (2007) states that individuals, who are believed as the fear seekers, it's actually sensation, novelty-seeking individuality which operates the wish to watch such types of movies. Such persons can predict the high risk, low fear behavior between different persons.

Maxfield (2003) finds out that why people go to movies to see the film they watch. He finds that stars of movies, the directors, advertising, trailers, spoken message, the subject matter and the reviews by the collection of the record of a specimen from 400 respondents at many theaters in the central and the north central Florida. Finding depicts that every base is having a relation with the choice of movie. Sparks (2000) consider the factors of the process of excitation transfer, different wiring and curiosity as reason of horror movie viewing. He argues that in the process of excitation transfer heart rate blood pressure and the respiration of the people increases. He noted that when the film is over the physiological excitation remains. However, in different wiring some people who just want to enjoy higher level of physiological excitation. Cantor (2014) finds that the reason watching of horror movies is unfamiliarity; there are some people who watch horror movies because they are unfamiliar with them. Almost everyone wants to know about unusual happenings in our surroundings. The danger upset our routine but the strangeness about any change is fundamental for life. Visual effects in the movies are also a reason of attracting the viewers, which tend to be fantastic. Cantor argues that after watching "Jaws," there are few people who felt strange about swimming in oceans and are frightened of pools and lakes.

Other people may avoid that films which come too close to their home. However, Kim (2012) argues in his article why do we watch scary movies? He finds that it is a way of experiencing fear in a controlled setting and excitement of riding a roller coaster causes an increase in adrenaline and increases heart rate without having any real effect.

Andrade and Cohen (2007) argue that people want to experience both negative, positive feeling together. They claim that there are some people who can be, "happy to be unhappy" and it is deep when a person have gone through a "psychological disengagement" or distance from being safe the result can be positive feelings.

More signs come from a series of investigation most of which has been conducted in 80 and 90 s, the era when the popularity of horror films was rising. It looked at the differences between individuals on the utilization of horror movies. Many persons don't enjoy horror, in spite of the fact that there are many who like viewing it. Who are the persons that pay to catch fear? Hoffner and Levine (2005) conducted meta-analyses 35 related articles that were in media psychology, it highlights the basic related traits which are the effective reaction, understanding, excitement seeking, aggressive nature, gender and the age. In account with age, it is noted that amusement increases in childhood. It is at its peak in teen age and then it gradually starts disappearing with age.

\section{Effects of Horror Movies:-}

Research on the effects of mass media was started when significant effects on the mind and behavior of people were observed. If we go through the history of research on the mass media affects, the first attempt to know the effects of movies were penny fund studies, a series of studies which reported serious effects on the children. This industry evolved and progressed with time and development in technology. The use of visual and sound effects in movies made them more realistic and effective. Previous research on the effects of movies depicted that people who often expose to movies are affected by the message or the theme of movies. It is obvious that movies with different genre have kind of effects on behaviors and attitudes of people. Dale cited in Neuendorf (2002) studied film contentcategorized films into 10 groups and found that more than $75 \%$ fall into Crime, Love and Sex categories, and same kind of trend probably seen today. Movies with horror genre are also very popular in all societies and caste of people, especially in youngsters. Studies find that children and adults have different effects on them.

It is examined in Pyne fund studies that it is an old age debate that does the horror movies really caused a definite negative effect on the human psyche? Many of the researchers believe in the theory that by passing the time, each generation becomes more desensitize to disturbing images. Adding that early black and white horror films were taken casually because they had a simple story line and lack of special effects but in 1972 the world of horror flicks was completely changed. The Exorcist is mostly considered as the most controversial movie of this genre. Most of the viewers say in theaters when they are asked about the release of this movie that people left the theater screaming. 
People believe that the film broke the ground for all other horror films competing for the scariest scenes, disturbing images and story lines and it raised the bar for filmmakers. Some viewers also reported that they were institutionalized psychiatric shortly after experiencing this film (Jacobs, 1990).

Badmington (2001) argues that 1978 Invasion of the Body Snatchers was released and it is also blamed for negative effects on the viewers. Ghost watch was released in 1992 and it is also categorized along with The Exorcist and Invasion of the Body Snatchers for increasing the population of psychiatric facilities across America. He argues that the exception doesn't a rule that people who are suffering major mental trauma after watching disturbing images and at the same time digesting a disturbing story line. He explains that mental diseases are mostly caused by predisposed chemical imbalances but it is also possible that someone suffers from mental illnesses caused solely by environmental issues. It is the most common mental disease and some experts might argue that PTSD (posttraumatic stress disorder) is commonly caused by real life events, the one who suffer it, is not able to draw a line between fiction and reality properly. The horror movie fans can better distance and frame psychologically making them more mentally stable. Barker and Petley (2002) argue on representations of horror and violence, whether real or fake, can cause lasting damaging effects on children. Children eight years or younger can be especially affected by this type of movies and television shows. They do not have the ability to understand that what is real and what is not and when a scary movie monster can temporarily scare an adult or older child, such images may last in younger minds of children.

Johnston (1995) discuss that some people really intend to be scared by horror movies. Viewers like some of the most horrified faces which are shown in the best horror films of Hollywood. The horror movie fans are keen to watch the distorted images and scary faces with blood dripping down. It is acceptable to watch these scary flicks just for entertainment if you do not share the situations shown in this movie. But if you start developing fearing for almost everything around you then it can be signed of caution. It is discussed that there are many cases which show that violent scenes shown in horror movies had affected the physical and psychological health of viewers. It may create fear, anxiety, sleeping disorders, phobia, and mental trauma while repeated exposure also helps viewers to desensitize with these effects. Johnston finds the relationship between violent media, cognitive and affective responses that are results of the aggression.

There are some effects that observed in the studies (Yoshihara et al. 2016; Rowsell and Generation, 2016; Albrecht, 2016; Barker and Petley, 2002) by watching horror movies i.e. anxiety, sleeping disorders, fear, phobia, animal, environment, blood/injury or injection, situation, sound and disturbing visuals. These effects bring mental disorders and brought behavioral changes in the viewers of the horror movies. Hence, the findings reveal the significant relationship between horror movies and response to cognition that brought the following effects.

1. Anxiety is one of the visible effects of scary films on youngsters and adults. Heart rate, blood pressure, and the production of adrenaline may increase by watching the horror movies. After completing the tension, (s) he may feel the excitement.

2. A sudden psychological effect of horror movies on viewers is reduced sleep. It might cause the inability to sleep through the night for few days, even months after watching the horror movie. The victim may start to use a nightlight in the bedroom while sleeping. Helshe can be disturbed by wild imaginations of the scary characters of the horror movie and this situation may disturb and lead to sleepless nights.

3. The exposure of horror genre is often characterized by fear. A viewer may become afraid of the darkness, cry, scream, tremble, shake or even nauseate, if the horror film has really scared him/her. It can also cause fear of losing control and fear of dying.

4. Watching the situations represented in the horror film may cause a phobia towards animals such as mammals, insects, reptiles, fire, flood, water, blood, injections, injury from a height and enclosed spaces.

5. Horrible faces and loud noises can also disturb the mind of viewers. Fires, floods, earthquakes, storms, water, nuclear holocaust and other environmental threats are also caused cognitive affect on viewers of horror movies. Blood, gore, injury, pain, wounds, needles and other physical threats to living things are also considered as horrifying objects. Space and dimensions is an important feature of horror movies. The viewers find frightening from heights, enclosed spaces and circumscribed situations like doctors' offices and sounds/Images i.e. disturbing sounds, distorted images loud noises, distorted faces bring traumatic effects on viewers. 


\section{Mental Trauma:-}

Horrifying and disturbing images can cause a mental trauma in the viewers. Studies (Pearce and Field, 2016; Clements and Sinclair, 2016; Souza, 2016) confirm that post traumatic stress disorder (PTSD) is very common among those people and persons that are suffering from PTSD may unable to differentiate between reality and fiction. Clements and Sinclair (2016) argue that the people who are willing to watch horror movies should be mentally stable, otherwise, it may cause depression. Souza (2016) discuss these effects of horror movies on teens and finds though we cannot easily predict that who will suffer from an anxiety disorder or phobia by a horror movie, but children and teens might be at higher risk than adults. She argues that parents know their kids best, so they should think about their overall development when they decide that what to let them watch. Those kids who are normally anxious, frightened have not enough ability of making difference in reality and fantasy should skip horror films for a few more years. May and Wisco (2016) find significant correlation between the proximity and indirect exposure to PTSD.

Many people might be disturbed by noises, shadows, or some disturbing dreams during sleep but these effects mostly persist for short time period. There can be some cases in which someone may face the disturbance in sleeping for weeks, months or even years. Shaw (2016) cited Carl Jung that he explains that the collection of negative and socially unacceptable tendencies that are a basic part of human nature. He believed that the shadow is an intrinsic part of what makes people human, and that battling it periodically is essential to growth and development. The horror movie provides a safe substitute for the real world, where kids can explore their darker instincts, impulses and fears without real-life implications. Piaget (1969) finds that schemas are responsible for our cognitive development that is ways of understanding the world. With the process of growing and learning our schemas get change. Most of the children and teens have put them at risk for developing anxiety or phobias that do not yet have the life experience to put horror movies into perspective. Kruuse and Kalmus (2016) argue on the behavioral changes by watch scary scenes in movies and finds that it affects negatively the reflex changes of a viewer and such people get shocked when they face such situations.

\section{Desensitization Effect of Watching Horror Movies:-}

There are also some advantages of watching horror movies. If a person watches these movies regularly, can be desensitize to violence which affect his behavior. It is also possible that they become less sensitive to tough situations in real life and feel that they are used to such hard situations. Horror films can also helpful to therapists in treatment of fears and phobias. Rydell (2016) studies the hypotheses related to violent media exposure and callousunemotional traits and finds no support. Cantor (2002) conducts a study and allowed the people to share their experiences of watching different scary films and how did they affected their lives during sleep or awake and got 530 descriptions. More than $1 / 3$ of the respondents told that horror movies have marginally significant affects but they are prone to desensitize from horror effects. These results support the view that movies can create the phobias and also have desensitization effects on emotional memory. Preceding this study Cantor et al. (2007) conducted an interview of 90 students (kindergarten to second graders) and 129 students (third to sixth graders) and asked the questions about the frightening media, significant respondent who expose to repetitive exposure to horror movies observed the desensitization effect. The respondents reported that they are neither find violence nor frightening visual having adverse effect on their emotions.

Desensitization is major media effect that is studied by numerous scholars, this effect reduce the emotional arousal and create antisocial behavior. The individuals who indulge in desensitization they reduce to intervene in fights and find least sympathies for effected of victims of violence. Cantor (2002) finds that there is bidirectional relationship between violence observed through horror movies and antisocial behavior. He concludes that movie rating and mass media literacy program should launch to educate the teenagers and adolescence to reduce the effect of movies and mass media. Hence, the following hypotheses are drawn in the study:

$\mathrm{H}_{1}$ : It is more likely that horror movies trigger psychological effects (i.e. fear, anxiety, phobia, PTSD feeling) in viewers of horror movies.

$\mathrm{H}_{2}$ : It is more likely that female viewers are highly affected by horror movies as compare to male viewers.

$\mathrm{H}_{3}$ : It is more likely that the youngsters who watch frequently horror movies are Desensitized as compare to those who watch less frequently horror movies.

$\mathrm{H}_{4}$ : The youngsters who believe that the horrifying characters shown in horror movies exist in reality are more fearful as compare to those who do not believe. 


\section{Methodology:-}

Survey research method is considered to be an appropriate method to the requirements and nature of this study to explore the effects of horror films on youngsters. The data is collected from the students of age 18 to 24 . They were asked different questions about their exposure to horror movies and that why they expose to these types of movies. In this study, the population is all male and female youngsters of Sargodha and Lahore who watch horror movies. The students enrolled in the universities in Sargodha and Lahore who watch the horror movies are the unit of analysis in this study. A sample of 640 students (320 male 320 Female) is selected from Sargodha and Lahore who watch horror movies. In this study for survey research, convenience or purposive sampling technique is used to collect the data. In this research study, a well-structured questionnaire is used to collect the data from university students who watch the horror movies. It consists of two sections. The first section of questionnaire is designed to elicit personal and demographic information from the respondents such as gender, education, age and location while the second section contains 22 questions about their watching habit of the movies, purposes of watching these movies, about their feelings and prior beliefs and fears of these objects and places which are shown in these movies. Cronbach's alpha $(\alpha)$ is 0.923 .

\section{Results and findings:-}

During the survey most of the respondents told that their favorite genre in movies is romantic genre (32.8\%). The other two genres which are most liked by the students are horror and comedy told by $(27.5 \%)$ and (24.1\%) respondents respectively (Table1). It shows that more male respondents $(35.2 \%)$ like the romantic genre while the tendency of liking horror movies is not significantly different in both genders i.e. (27.2\%) male respondents and $(27.8 \%)$ female respondents.

Table 1:- Favorite genre in movies

\begin{tabular}{|l|l|l|l|l|l|}
\hline \multirow{2}{*}{} & \multirow{2}{*}{ Overall } & Gender & Locality \\
\cline { 3 - 6 } & & Male & Female & Sargodha & Lahore \\
\hline Romantic & 32.8 & 35.2 & 30.4 & 31.2 & 34.3 \\
\hline Horror & 27.5 & 27.2 & 27.8 & 27.9 & 27.1 \\
\hline Comedy & 24.1 & 23.5 & 24.7 & 19.5 & 28.3 \\
\hline Action & 0.9 & 12.3 & 17.1 & 19.5 & 10.2 \\
\hline
\end{tabular}

The students are asked that why they expose to horror movies, they respond that the entertainment is the first big reason for which most of the respondent (51\%) expose to horror movies frequently while curiosity for which they expose to horror movies very frequently (47.6\%). More than half of the respondents $(52.5 \%)$ respond that they are not addicted to watch horror movies. (see Table 2). These results are in line to Sparks et al. (2012), where he agrees that horror movies are viewed because of excitement transfer and entrainment.

Table 2:- Purposes of watching horror movies

\begin{tabular}{|l|l|l|l|l|l|}
\hline Purposes & Very often & Often & Sometimes & Rarely & Not at all \\
\hline Excitement & 18.1 & 21.3 & 26.9 & 16.3 & 17.5 \\
\hline Escapism & 10.9 & 8.8 & 26.3 & 19.4 & 34.1 \\
\hline Peer pressure & 14.1 & 8.8 & 20.9 & 24.1 & 32.2 \\
\hline Time pass & 16.3 & 19.4 & 29.4 & 19.7 & 15.3 \\
\hline Entertainment & 23.8 & 27.2 & 24.4 & 15.6 & 9.1 \\
\hline Thrill & 19.7 & 23.1 & 25.6 & 14.4 & 17.2 \\
\hline Curiosity & 23.8 & 23.8 & 21.3 & 15.3 & 15.9 \\
\hline Addiction & 8.8 & 10.6 & 16.6 & 11.6 & 52.5 \\
\hline
\end{tabular}

Figure 1 demonstrates that (43.8\%) of respondents feel much excited when they see a horror movie, while (32.8\%) respondents seldom excited or do not feel excited at all. Whereas, $(42.2 \%)$ do not feel joyful or rarely feel joyful when they watch a horror movie, while (34.7\%) feel much joyful after watching a horror movie. The feelings of fear are felt very much by $(40.3 \%)$ of respondents' contrary $(34.7 \%)$ of students do not or rarely feel fearful after watching a horror movie. The negative feelings like anxiety, depression and insecurity are felt much by (31.6\%), (18.2\%) and (20.9\%) of respondents respectively. Sparks et al. (2012) confirm that when someone feels positive 
feeling, enjoy and have they come to do it again. So here, we can say that excitement the respondents feel after watching a horror movie appeals the youngsters to watch horror movies again.

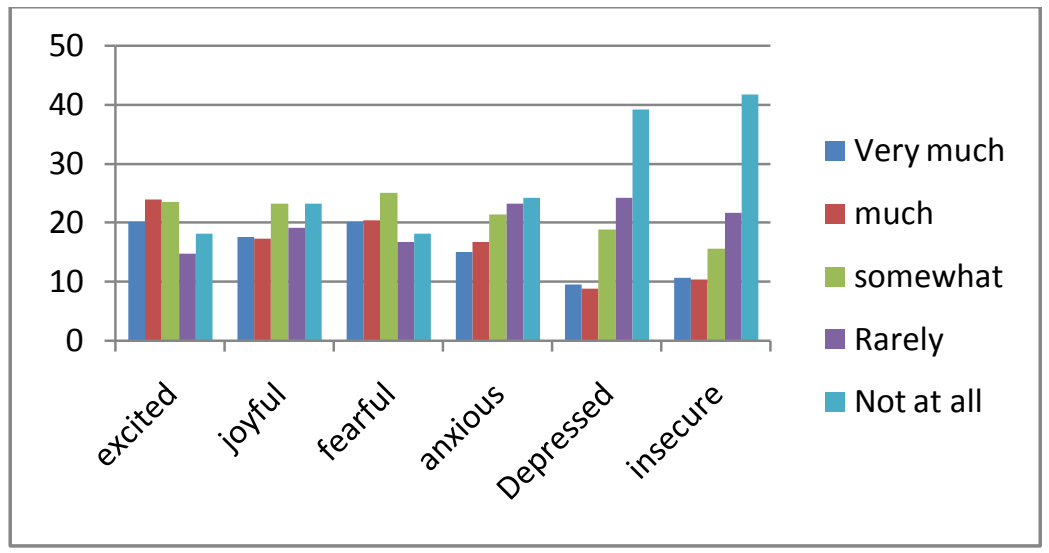

Fig 1:- Feelings after watching a horror movie

If we compare the gender and locality of the respondent to know that who is feeling more fearful after watching a horror movie, it can be seen (Table 3) that more than (20\%) of the female students are feeling very much fearful while nearly $(18 \%)$ of the male students are feeling very much fearful. By comparing locality we can figure out those fearful feelings much are mostly felt by the students $(41.6 \%)$ who belong to Lahore as compare to those who belong to Sargodha (38.9\%).

Table 3:- Time period of feelings fearful

\begin{tabular}{|l|l|l|l|l|l|l|}
\hline Category & For hours & For a day & For couple of days & For weeks & For couple of weeks & For months \\
\hline Very often & 22.5 & 15.6 & 9.7 & 3.4 & 2.8 & 1.9 \\
\hline Often & 31.6 & 15.9 & 6.6 & 6.9 & 3.4 & 2.8 \\
\hline Sometimes & 13.8 & 14.4 & 13.9 & 9.1 & 6.6 & 4.4 \\
\hline Rarely & 16.9 & 21.9 & 18.4 & 20.3 & 14.7 & 11.9 \\
\hline Not at all & 15 & 32.2 & 51.6 & 60.3 & 72.5 & 79.1 \\
\hline
\end{tabular}

During the survey the students were asked that if they find any change in their sleeping behavior after watching a horror film. (38.8\%) of students told that they often feel disturbance in sleeping after watching a horror movie while $(45 \%)$ of the students respond that they rarely or do not feel any disturbance in sleeping. Nightmares and wild imagination disturbed often (26.2\%) and (27.8\%) students respectively while more than (50\%) replied they rarely or do not have any nightmares or wild imaginations after watching a horror movie (Fig 2). The findings are in line to Andrade and Cohen (2007). They find that horror movies are viewed both for negative and positive purpose. The effects can be gauged depending upon the situation, the viewer is engaged. 


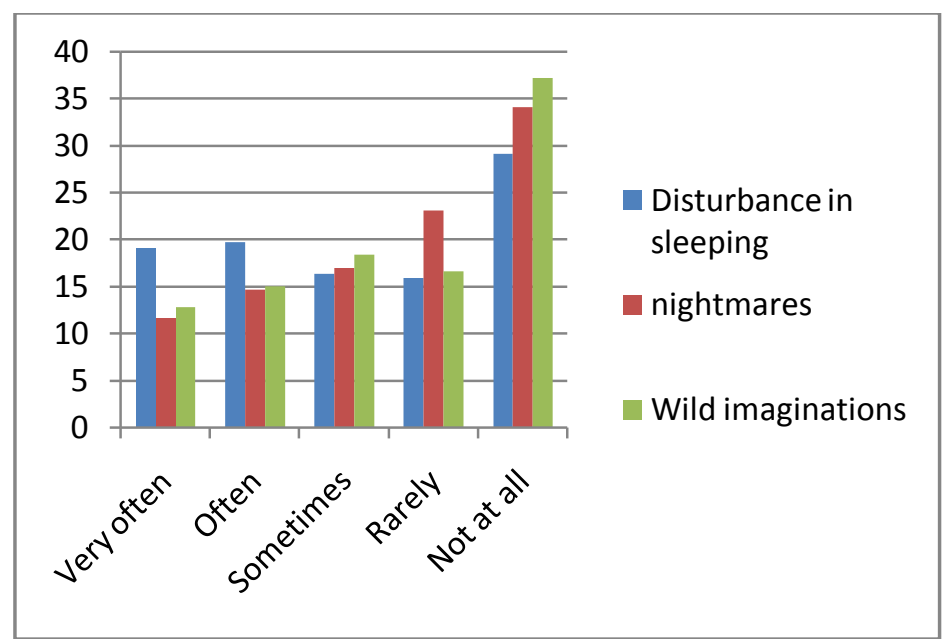

Fig 2:- Change in sleeping behavior

The respondents were asked that if they believe in the existence of the horrifying characters (Dracula, zombies, ghost, monsters, and any other supernatural object). The significant respondents (58\%) do not believe in the existence of Dracula and zombies while it is believed by the most of respondents (39.4\%) that Dracula exist in real life. The results are contrast to Badmington (2001), he finds that post traumatic stress disorder (PTSD) is having a correlation with the real life events rather movies. He asserts that predisposed chemical imbalance caused the distorted visuals to the suffered individual, and it is hard enough for him/her to draw difference between reality and fiction.

To make a comparison between males and females that who believe more in the existence of these characters two separate figures are shown below (Fig 3, Fig 4). Fig 4 reflects that more male respondents (20.6\%) believe in the existence of Dracula much than female respondents i.e. (13.2\%) (Fig4.4). It can be seen that more female respondents (25.7\%) (Fig4.4) believe much in the existence of any supernatural objects as compare to male respondents. Hoffner and Levine (2005) are confirmed that gender and age link with level of excitement and curiosity to know about new things. They find that with the passage of time, it is fadeout.

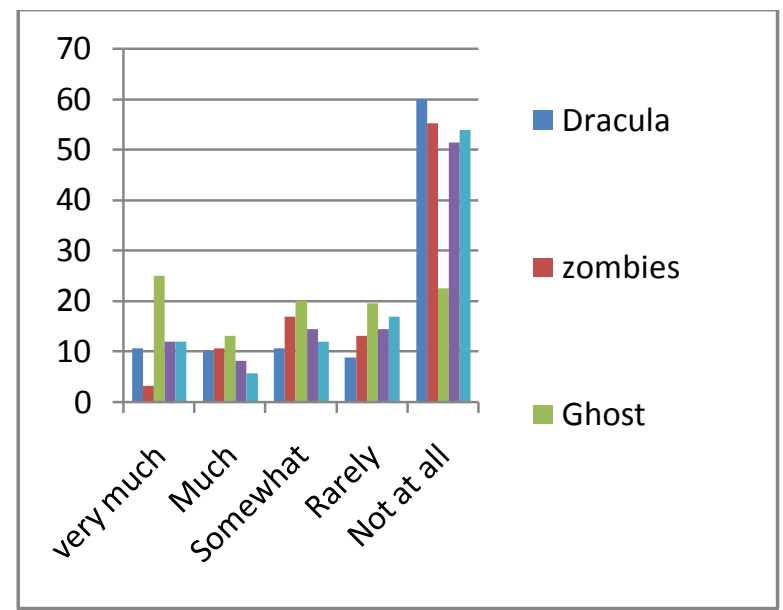

Fig 3:- Males who believe in the existence of horrifying characters

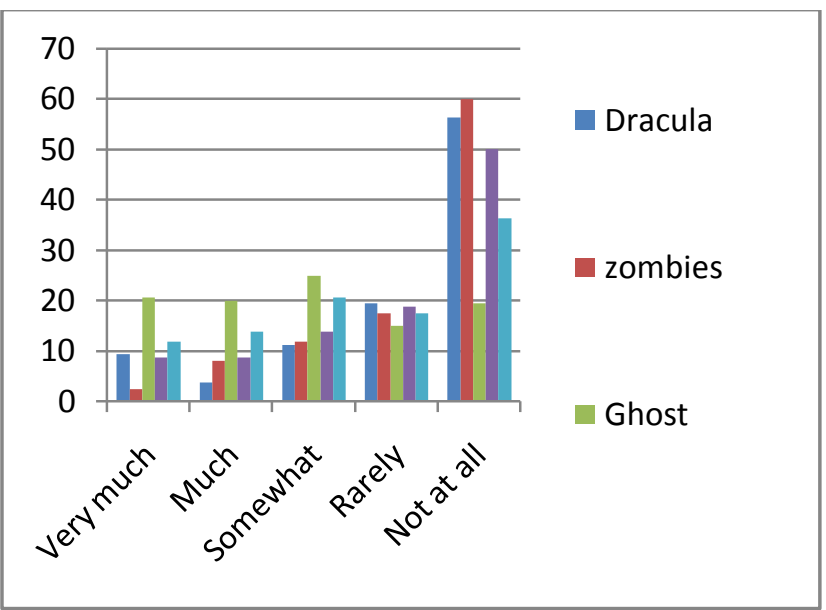

Fig 4:- Females who believe in the existence of horrifying characters 
Table 4:- Fear of objects

\begin{tabular}{|l|l|l|l|l|l|}
\hline & darkness & Loneliness & $\begin{array}{l}\text { Thundering } \\
\text { lightening }\end{array}$ & Sounds & old trees \\
\hline Very much & 24.1 & 23.8 & 15.9 & 15 & 15 \\
\hline Much & 26.3 & 23.8 & 12.5 & 15.3 & 12.2 \\
\hline Sometimes & 18.1 & 20.6 & 22.2 & 18.4 & 15.3 \\
\hline Rarely & 18.4 & 16.9 & 20 & 23.4 & 16.9 \\
\hline Not at all & 13.1 & 15 & 29.4 & 27.8 & 40 \\
\hline
\end{tabular}

The (Fig. 5) reflect that majority of the respondents (39.4\%) believe much in the existence of horrifying characters because of their religious beliefs. On the other hand, a significant majority of people said that personal experience (48.1\%) or any other reasons $(56.3 \%)$ are not the reasons of believing these characters in reality.

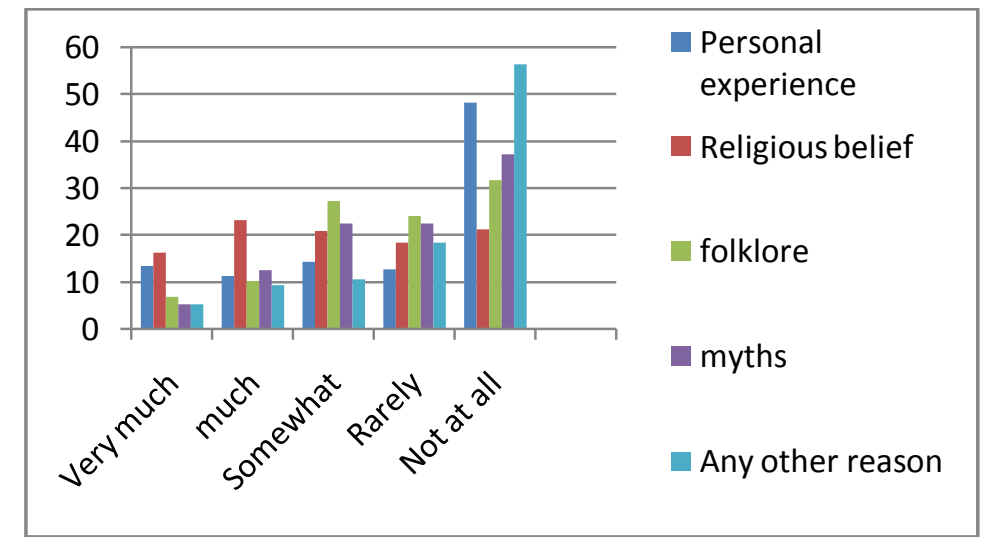

Fig 5:- Reasons of believing the existence of horrifying characters in reality

The respondents are asked that if they get afraid of these objects (darkness, loneliness, thundering \& lightening, sounds, and old trees) after watching a horror movie. Table 4 demonstrates that most of the students are much afraid of darkness $(50.4 \%)$ and loneliness $(47.6 \%)$. On the other hand, most of the students (56.9\%) replied that they are rarely or not afraid of old trees. These findings support the (Neuendorf 2012) that one's emotional response associated with specific objects, settings or actions that are portrayed in the movie. Bundara (1994) argues that the process of social cognition is directed conceptually and metaphorically by the information sources, where the media considered as the main source of information that increase our efficacy and develop world view. Our behavior is an outlook of mediated reality. Social cognition theory chiefly point out the elements that are reason of our developed perception turned into behavior.

The Fig 6 shows that most of the students told that they often avoid to going graveyard (42.5\%) and old buildings $(40.4 \%)$. On the other hand most of the students told that they rarely or do not avoid at all to going forests (52.8) and hilly areas (62.2\%). 


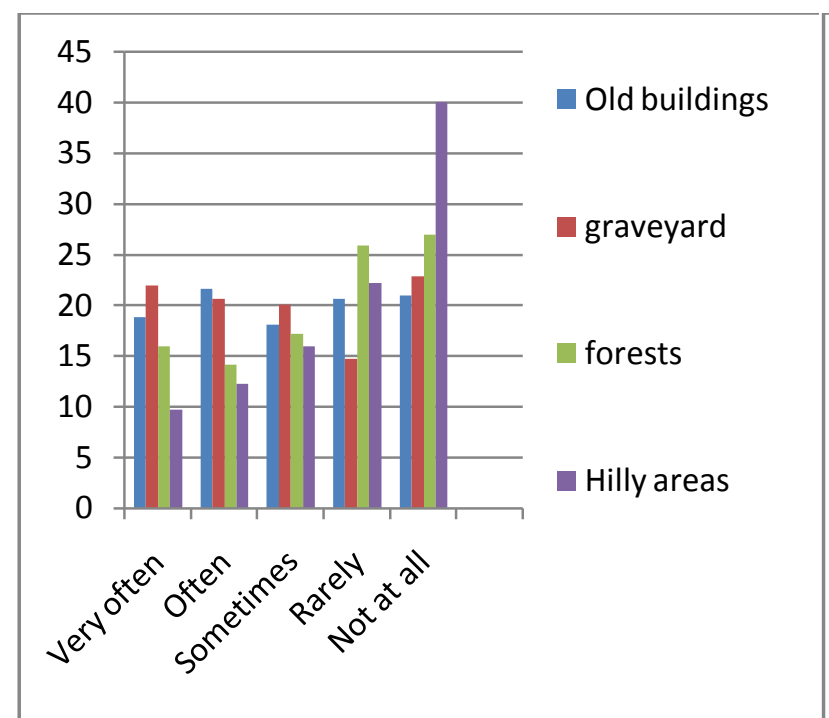

Fig 6:- Avoidance of going the fearful places

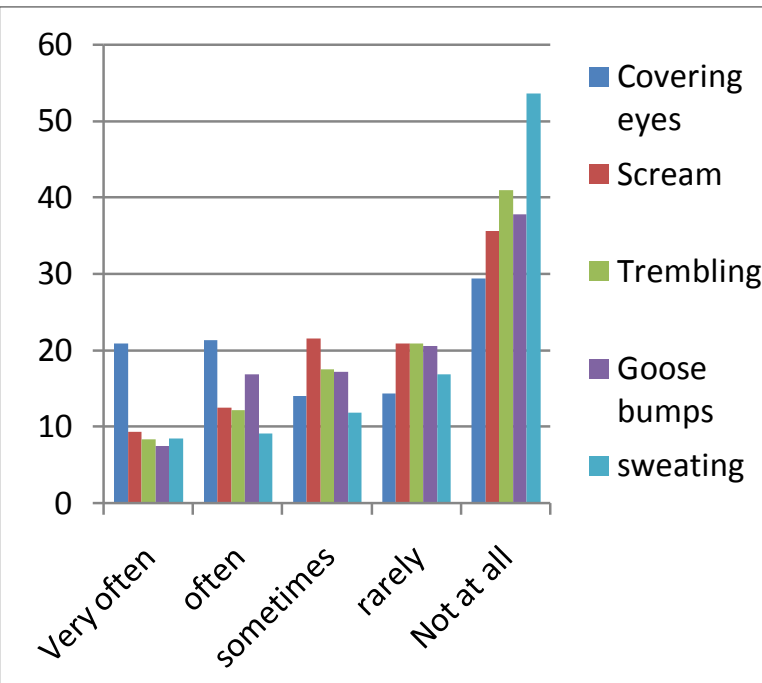

Fig 7:- Reaction when get frightened

Fig 7 illustrates that $(42.2 \%)$ of respondents told that they cover their often cover their eyes if they get frightening when watching a horror movie. Whereas, (21.9\%) of respondents scream often when they get frightened by watching a horror movie. A majority of respondents $(70.5 \%)$ replied that they rarely or do not sweat and tremble $(61.8 \%)$ when they get frightened.

The fig (8) shows that more female viewers cover their eyes $(50.1 \%)$, scream $(28.8 \%)$, tremble $(23.1 \%)$, goose bumps $(31.9 \%)$, and feel sweating $(18.2 \%)$ often when they watch horror movies as compare to male viewers. The results confirm (Kruuse and Kalmus, 2016) that horror movies cause reflex changing situation. Frightening, screaming and covering eyes are significantly effects the reflex process. Throughout much of the history of media effects research, great attention has been placed on the possible negative consequences media content can have on audiences' attitudes and behaviors (Bryant \& Zillmann, 2013). In current research social cognitive theory is tapped better to explain why such behavioral effects might emerge.

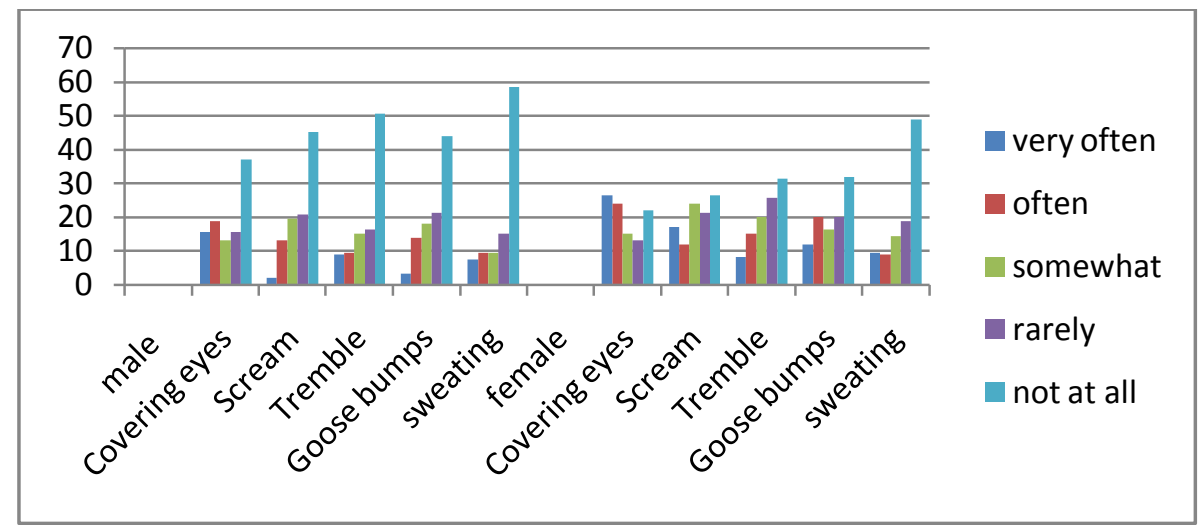

Fig 8: Reactions after watching a horror movie

(Comparison between male and female viewers)

Most of the respondents (32.2\%) replied that they have developed the phobia of dead bodies after watching a horror movie. The second majority of students (18.8) respond that they have developed the phobia of blood. Phobia of insects, water and height are developed by $(12.2 \%),(11.9 \%)$ and $(10.9 \%)$ of the respondents respectively. Whereas, $(14.1 \%)$ of the respondents replied that they have not developed phobia of these objects. The findings are in line with studies (Pearce and Field, 2016; Clements and Sinclair, 2016; Souza, 2016). The potential effects of horror movies can be observe as post traumatic stress disorder (PTSD) on the viewers. Hence, $\mathrm{H}_{1}$ is conclusive. 
Most of the participants (39.4\%) think that by watching horror movies repeatedly they become desensitize and less fearful while (30.3\%) are contrary to it. These findings are similar of Rydell (2016) and Cantor (2002) that observe the significant desensitization effect on viewers. It was hypothesized that female viewers are highly affected by horror movies as compare to male viewers. The data analysis shows that female viewers are more fearful as compare to male viewers. It can be seen in that more female viewers feel disturbance in sleeping, nightmares and wild imaginations as compare to male viewers. However, more females reacting fearfully as compare to male viewers. To check the significant t-test is applied to these variables which show that there is a significant difference in these effects of horror movies on male and female respondents.

The following Table (5) shows that p-value is lower than the level of significance $(\alpha)$ so hypothesis is accepted.

Table 5: Difference between male and female viewers influencing horror movies

\begin{tabular}{|l|l|l|l|l|}
\hline & & $\mathrm{t}$ & \multicolumn{1}{c|}{ Sig. } & M dif. \\
\hline Insecure & & 2.826 & .005 & .431 \\
\hline Disturbance in Sleeping & & 3.252 & .001 & .538 \\
\hline Nightmares & & 2.234 & .026 & .344 \\
\hline Wild imaginations & & 2.896 & .004 & .463 \\
\hline Cover your eyes & & 3.475 & .001 & .588 \\
\hline Scream & & 3.152 & .002 & .894 \\
\hline Trembling & & 2.285 & .023 & .338 \\
\hline Goose bumps & & 3.320 & .001 & .488 \\
\hline
\end{tabular}

$\mathrm{p}>0.05$

The Table above (5) reflects that the female viewers feel more insecure, disturbance in sleeping, nightmares, wild imaginations, cover their eyes, scream, tremble and goose bumps after watching the horror movies. These all responses are outcome or effects of watching horror movies. It is obvious from the findings that female viewers are affected more than male viewers.

It is more likely that the youngsters who watch horror movies frequently have more nightmares as compare those who watch these movies less frequently. The results support the $\mathrm{H}_{2}$

Table 6 :- Long term Psychological effects on viewers of horror movies

\begin{tabular}{|l|l|l|l|l|l|l|}
\hline & & $\begin{array}{l}\text { Sum } \\
\text { Squares }\end{array}$ & & Mean Square & F & Sig. \\
\hline \multirow{2}{*}{ Nightmares } & Between Groups & 47.048 & & 5.885 & 3.152 & $.015^{*}$ \\
\cline { 2 - 7 } & Within Groups & 1167.41 & & 1.867 & & \\
\cline { 2 - 7 } & & & & & \\
\hline
\end{tabular}

$$
\mathrm{p}^{*}>.05
$$

It was hypothesized that people who expose to horror movies frequently have more nightmares as compare to those who watch rarely. ANOVA is applied to check that if there is any significant difference or not. The table above reflects that $\mathrm{p}$-value is less than $\alpha$ so the hypothesis $\left(\mathrm{H}_{3}\right)$ is accepted.

Believe in the existence of those horror characters which are shown in horror movies may increase the fear among viewers. The youngsters who believe that the horrifying characters shown in horror movies exist in reality are more fearful as compare to those who do not believe in their existence. It is hypothesized that the people who believe in the existence of horrifying characters feel more fearful when they watch horror movies as compare to those who do not believe in their existence. To address the statement that whether and to what extent believe in the existence of horrifying characters influences the effects of horror movies on youngsters (see Table 8). It supports the $\mathrm{H}_{4}$. 
Table 8:- Regression of the respondents who believe on horrifying characters

\begin{tabular}{|c|c|c|c|c|c|}
\hline \multicolumn{6}{|l|}{ Coefficients } \\
\hline \multirow[t]{2}{*}{ Model } & \multicolumn{2}{|c|}{ Unstandardized Coefficients } & \multirow{2}{*}{$\begin{array}{l}\text { Standardized } \\
\text { Coefficients } \\
\text { Beta } \\
\end{array}$} & \multirow[t]{2}{*}{$\mathrm{T}$} & \multirow[t]{2}{*}{ Sig. } \\
\hline & $\mathrm{B}$ & Std. Error & & & \\
\hline (Constant) & 1.252 & .326 & & 3.841 & .000 \\
\hline Dracula & .169 & .069 & .169 & 2.445 & .015 \\
\hline Ghost & .125 & .057 & .131 & 2.177 & .030 \\
\hline Monsters & .114 & .063 & .115 & 1.826 & .069 \\
\hline
\end{tabular}

Sig. > .01

Hence, horror movies create complex environmental advances that cause specific biological systems for functioning of perception. According to Bandura (1986) that social cognition is having relationship with reciprocal determinism and dynamic relationship with personal factors and environmental influences.

\section{Conclusion:-}

The present study evaluating horrific cinema from the hypotheses of psychological effects on college students of two cities of Pakistan explored in length different psychological effects on college going youth. The results support the literature and the hypotheses that horror movies have significant affect on college going students and it confirms the basic understanding of social cognition theory. The effects of horror movies become more visible when it has relationship with personal factors and environmental influence. Unfortunately, Pakistani nation is observing war against terrorism and the environmental factor is significant that can potentially influence the viewers of horror movies. Traces of different psychological effects i.e. anxiety, sleeping disorders, fear, phobia, animal, en vironment, injury or injection, situation, sound and disturbing objects are observed on viewers of horror movies that find that horror movies can trigger these psychological effects. These effects are considerable on female viewers as compared to male. However, repetitive exposure brought the desensitization effect that is prone to develop antisocial behavior among youngsters. However, believing on the existence of horror characters is shaving relationship with preexisting beliefs of the viewer. The individuals who already believe that such characters exist in reality are more frightened compared to those who do not have such beliefs. The implication of this study is on policy level. Government should ensure regulation to enforce rating type on all genres of movies so that all concern can make sure the scale of violence in the movies. Moreover, mass media effects are prevalent whereas the mass media literacy program should launch to reduce the psychological effects on youth.

\section{References:-}

1. Albrecht, K. (2016). Are You Scared? Readings on Genre Theory and Audience Engagement in Horror Cinema, Rutledge.

2. Bandura, A. (1994). Self-efficacy. John Wiley \& Sons, Inc.

3. Barker, M., \& Petley, J. (Eds.). (2002). Ill effects: The media violence debate. Routledge.

4. Bevan, R. (2007). The destruction of memory: architecture at war. Reaktion books.

5. Bryant, J., \& Zillmann, D. (2013). Responding to the screen: Reception and reaction processes. Routledge.

6. Cantor, J. (2000). Media violence. Journal of adolescent health, 27(2), 30-34.

7. Cantor, J. (2002). Fright reactions to mass media. Media effects: Advances in theory and research, 2(2), 287306.

8. D'Souza, R. (2016). Post-Traumatic Stress Disorder Cardiff| PTSD Cardiff. Retrieved on dated 1.06.16 from http://www.clinicalhypnotherapy-cardiff.co.uk/post-traumatic-stress-disorder

9. Giannetti, L. D., \& Leach, J. (1999). Understanding movies (1), 1, Upper Saddle River, New Jersey: Prentice Hall. p. 70.

10. Johnston, D. D. (1995). Adolescents' motivations for viewing graphic horror. Human Communication Research, 21(4), 522-552.

11. Kavanagh, D. J., Freese, S., Andrade, J., \& May, J. (2001). Effects of visuospatial tasks on desensitization to emotive memories. British Journal of Clinical Psychology, 40(3), 267-280.

12. Kruuse, K., \& Kalmus, V. (2016). Supernatural Creatures, Accidents, and War Young Children's Televisionrelated Fears and Coping Strategies Television \& New Media, doi: 10.1177/1527476416652692

13. Leathers, D. G., \& Eaves, M. (2015). Successful nonverbal communication: Principles and applications. Routledge. 
14. Maxfield, S. M. (2003). Media at the movies: Analyzing the movie-viewing audience (Doctoral dissertation, University of Florida). Retrieved from http://etd.fcla.edu/UF/UFE0001560/maxfield

15. May, C. L., \& Wisco, B. E. (2016). Defining trauma: How level of exposure and proximity affect risk for posttraumatic stress disorder. Psychological trauma: theory, research, practice, and policy, 8(2), 233.

16. Mezias, S. J., \& Kuperman, J. C. (2001). The community dynamics of entrepreneurship: the birth of the American film industry, 1895-1929.Journal of Business Venturing, 16(3), 209-233.

17. Morreall, J. (1993). Fear without belief. The Journal of Philosophy, 90(7), 359-366.

18. Pearce, L. J., \& Field, A. P. (2016). The Impact of "Scary" TV and Film on Children's Internalizing Emotions: A Meta-Analysis. Human Communication Research, 42(1), 98-121.

19. Pearce, L. J., \& Field, A. P. (2016). The Impact of "Scary" TV and Film on Children's Internalizing Emotions: A Meta-Analysis. Human Communication Research, 42(1), 98-121.

20. Piaget, J. (1971). The theory of stages in cognitive development. Readings, p.?

21. Rowsell, J. (2016). Staying Up Late Watching The Walking Dead. InGeneration Z (pp. 101-113). Springer Singapore.

22. Rydell, A. M. (2016). Violent media exposure, aggression and CU traits in adolescence: Testing the selection and socialization hypotheses. Journal of Adolescence, 52, 95-102.

23. Sanders, M. R. (2008). Triple P-Positive Parenting Program as a public health approach to strengthening parenting. Journal of family psychology, 22(4), 506.

24. Shaw, B. (2016). Developments in The Neuroscience Of Dreams: The Journal for Neuro-cognitive Research, 58(1-2).

25. Sinclair, N. D. (1993). Horrific traumata: A pastoral response to the post-traumatic stress disorder. Haworth Press.

26. Sparks, G. G., \& Sparks, C. W. (2000). Violence, mayhem, and horror. Media entertainment: The psychology of its appeal, 4 (2)73-92.

27. Walton, D. N. (1989). Informal logic: a handbook for critical argument. Cambridge University Press.

28. Wong, K. T., Teo, T., \& Russo, S. (2012). Influence of gender and computer teaching efficacy on computer acceptance among Malaysian student teachers: An extended technology acceptance model. Australasian Journal of Educational Technology, 28(7), 1190-1207.

29. Yoshihara, K., Tanabe, H. C., Kawamichi, H., Koike, T., Yamazaki, M., Sudo, N., \& Sadato, N. (2016). Neural correlates of fear-induced sympathetic response associated with the peripheral temperature change rate. NeuroImage, 134 (2), 522-531. 